\title{
Effects of sharing information on drug administration errors in pediatric wards: a pre-post intervention study
}

This article was published in the following Dove Press journal:

Therapeutics and Clinical Risk Management

23 March 2017

Number of times this article has been viewed

\author{
Siew-Siang Chua' \\ Sim-Mei Choo' \\ Che Zuraini Sulaiman² \\ Asma Omar \\ Meow-Keong Thong ${ }^{3}$ \\ 'Department of Pharmacy, Faculty \\ of Medicine, University of Malaya, \\ ${ }^{2}$ Pharmacy Department, University \\ Malaya Medical Centre, ${ }^{3}$ Department \\ of Paediatrics, Faculty of Medicine, \\ University of Malaya, Kuala \\ Lumpur, Malaysia
}

Background and purpose: Drug administration errors are more likely to reach the patient than other medication errors. The main aim of this study was to determine whether the sharing of information on drug administration errors among health care providers would reduce such problems.

Patients and methods: This study involved direct, undisguised observations of drug administrations in two pediatric wards of a major teaching hospital in Kuala Lumpur, Malaysia. This study consisted of two phases: Phase 1 (pre-intervention) and Phase 2 (post-intervention). Data were collected by two observers over a 40-day period in both Phase 1 and Phase 2 of the study. Both observers were pharmacy graduates: Observer 1 just completed her undergraduate pharmacy degree, whereas Observer 2 was doing her one-year internship as a provisionally registered pharmacist in the hospital under study. A drug administration error was defined as a discrepancy between the drug regimen received by the patient and that intended by the prescriber and also drug administration procedures that did not follow standard hospital policies and procedures. Results from Phase 1 of the study were analyzed, presented and discussed with the ward staff before commencement of data collection in Phase 2.

Results: A total of 1,284 and 1,401 doses of drugs were administered in Phase 1 and Phase 2, respectively. The rate of drug administration errors reduced significantly from Phase 1 to Phase 2 (44.3\% versus $28.6 \%$, respectively; $P<0.001$ ). Logistic regression analysis showed that the adjusted odds of drug administration errors in Phase 1 of the study were almost three times that in Phase $2(P<0.001)$. The most common types of errors were incorrect administration technique and incorrect drug preparation. Nasogastric and intravenous routes of drug administration contributed significantly to the rate of drug administration errors.

Conclusion: This study showed that sharing of the types of errors that had occurred was significantly associated with a reduction in drug administration errors.

Keywords: drug administration error, medication error, intervention, sharing, pediatric

\section{Introduction}

Medication errors increase the risk of morbidity and mortality, which may result in direct, indirect and intangible cost to the patients, their families as well as the community and the country as a whole. ${ }^{1}$ On an average, a hospitalized patient is subjected to at least one medication error per day and at least 1.5 million preventable adverse drug events occur every year. These errors and events incur at least USD3.5 billion additional hospital costs annually in the USA. ${ }^{1}$

Medication errors can occur at any stage of the medication use process, but thus far, most of the studies have been on prescribing, dispensing and administration.
Correspondence: Siew-Siang Chua Department of Pharmacy, Faculty of Medicine, University of Malaya, 50603

Kuala Lumpur, Malaysia

Tel +60193363223

Fax +60 379674964

Email chua_ss@hotmail.com 
A 5-year analysis of reported medication errors in Hong Kong concluded that $92.4 \%$ of all drug administration errors reached the patient. ${ }^{2}$ It has been reported that children are particularly vulnerable to medication errors, with a higher incidence of errors than that in the adult population. ${ }^{3}$ Direct observational studies reported that drug administration error rates in pediatric patients ranged between $9.6 \%$ and $40.4 \% .{ }^{4-11}$ A study in Nigeria reported a higher drug administration error rate of $89.9 \% .^{12}$ The wide variation in error rates is probably due to the different study designs, definitions used, denominators of error rate, types of observation, sampling methods and settings. ${ }^{13,14}$ However, the findings of these studies indicate that drug administration errors are common and more likely to cause patient harm as less checkpoints are in place compared to the prescribing stage. Therefore, interventions at the drug administration stage is crucial.

A majority of studies on drug administration errors in pediatric patients were conducted in developed countries. $4,5,7,7,10$ Thus far, in Malaysia, only two studies on drug administration errors in the pediatric population have been identified in the literature. ${ }^{6,11}$ These studies showed that such medication errors are also common in developing countries such as Malaysia.

Research on medication errors had been on the rise, but emphasis should be on preventive strategies, with assessment of baseline error rate being essential. ${ }^{1}$ Studies on interventions to reduce drug administration errors included various educational programs to impart knowledge to the staff involved on the correct procedures in drug administration. ${ }^{5,9,11,15}$ However, such studies are still scarce in Malaysia. Therefore, the present study was conducted to determine the effects of sharing information on drug administration errors in pediatric wards among the health care providers.

\section{Patients and methods Study setting}

This study consisted of two phases: Phase 1 (pre-intervention) and Phase 2 (post-intervention). Both phases involved direct, undisguised observation of drug administrations in two pediatric wards of a major teaching hospital in Kuala Lumpur, Malaysia.

The two pediatric wards included in this study consisted of an 18-bedded and a 19-bedded pediatric general medical ward (Ward A and Ward B, respectively), which were for patients aged $\leq 16$ years. Ward A and Ward B had a total of 21 and 25 nursing staff, respectively. These wards practiced the ward stock system and unit-of-use as explained in the previous study. ${ }^{6}$ At the time of this study, there were no clinical pharmacists attached to the wards, and hence, prescriptions would only be screened by pharmacy staff if they were presented to the inpatient pharmacy to obtain unitof-use medications for a particular patient.

A medication nurse was responsible for preparing and administering drugs to all the patients in the ward, but if she was not available, the nurses responsible for each part of the ward would administer the medications. Administration of drugs through intravenous injection was performed by house or medical officers in the hospital under study.

The method used in this study, including the definition of the types of errors, was adopted from a previous study that was conducted in the same hospital but in different wards. ${ }^{6}$ The main difference between the two studies is that the present study involved an intervention to share information on the types of drug administration errors that occurred in the pediatric wards.

\section{Definitions of drug administration errors}

A drug administration error was defined as a discrepancy between the drug regimen received by the patient and that intended by the prescriber and also drug administration procedures that did not follow standard hospital policies and procedures. ${ }^{6}{ }^{6} 16$ Drug administration errors in this study were classified into eight main categories (similar to that of other studies): omission errors, incorrect dose, incorrect administration time, incorrect administration technique, incorrect drug preparation, unauthorized drug, deteriorated drug and other errors (those that could not be classified into any of the seven categories mentioned). ${ }^{6,8,10,17}$ Nasogastric tube-related errors were classified and described with reference to studies in the literature. ${ }^{18-21}$

Incorrect administration time is defined as the administration of a dose $>60$ minutes before or after the scheduled time. Incorrect administration technique included incorrect rate of administering a drug, incorrect route and deviation from drug administration procedures or guidelines. Incorrect drug preparation included not mixing or shaking a suspension thoroughly before taking out the dose, tablets not cut evenly, crushing of specially coated tablets and incorrect method of dilution or reconstitution. Unauthorized drug is when an ordered drug is given to the wrong patient, a patient is given the wrong drug and an unordered drug or dose is given. Deteriorated drug is the administration of an expired drug.

\section{Intervention}

The intervention in this study was the sharing of Phase 1 findings with the ward staff and to bring awareness of drug administration errors. This included a presentation of the study findings by one of the researchers (SSC who is an academician 
with 20 years of working experience and also a pharmacist) to medical staff from the Pediatric Department, followed by a "Question and Answer" session, which took a total of approximately 60 minutes. Another five sessions of presentation were carried out, followed by discussion on the findings of this study between two of the researchers (SSC and CZS who have been working as a pharmacist in the hospital under study for $>20$ years) and the nursing staff plus the medical doctors in both the wards under study. This was to involve as many staff as possible, especially the nursing staff who was on shift duties. Each session took about 30-45 minutes and was conducted during office hours but managed to involve about $90 \%$ of the ward staff.

\section{Data collection procedure}

Data were collected over a 40-day period in each phase of this study, with 20 days ( 5 working days for 4 weeks) in each ward. Data collection for Phase 1 of this study was conducted from January to March 2011 (excluding weekends and public holidays). Intervention was done in May 2011 where the findings from Phase 1 were presented and discussed with the ward staff before the commencement of data collection for Phase 2 of this study from June to August 2011.

The ward staff was informed that the researcher would be in the ward to observe how medications were administered. The observer was allowed to intervene any clinically significant errors to prevent patient harm, as practiced in other studies. ${ }^{6,22-24}$ However, these were still considered as errors.

Two observers ( 1 and 2 ) were involved in the observation of drug administrations and in collecting the data. This was to reduce errors in observation due to observer fatigue. However, the same observers were involved in both phases of the study to prevent observer bias. Both observers were involved in data collection for 20 days each in both phases of the study. Observer 1 was stationed in Ward A and Ward B on alternate working days, from 07:30 to 19:30 hours, for the first 20 days of the study, followed by Observer 2 for another 20 days. Both observers were pharmacy graduates: Observer 1 just completed her undergraduate pharmacy degree, while Observer 2 was doing her one-year internship as a provisionally registered pharmacist in the hospital under study. The observer followed and observed the ward staff during the time of drug preparation until administration to the patient. All drug preparations and administrations to pediatric patients in the two wards were recorded in a data collection form. Drug administration by patients themselves or their caregivers without supervision of a ward staff, drug administration in emergency cases and in isolated rooms where an unauthorized person was not permitted as well as those administered between 19:30 to 07:30 hours and during the weekends and public holidays were excluded. Drug preparations conducted in the pharmacy were also excluded from this study.

After each round of drug administration, all recorded observations were compared with the doctors' original orders. These observations were also analyzed with reference to medication labels, manufacturer's instructions, standard hospital policies and procedures as well as accepted professional standards and guidelines. If there was any discrepancy, the observer would clarify it with the ward staff concerned. All possible drug administration errors were discussed with the research team, which consisted of a pharmacist and a pediatrician, both of whom were also researchers.

This study was approved by the Medical Ethics Committee of University Malaya Medical Centre (MEC Ref No 757.46). All the ward staff signed an informed consent form to be observed.

\section{Data analysis}

The rate of drug administration errors was calculated based on the number of doses with one or more errors $(\mathrm{nE})$ divided by the sum of observed doses (nA) and those ordered but omitted (nO). This was then multiplied by 100 to compute the percentage of drug administration errors. The denominator $(\mathrm{nA}+\mathrm{nO})$ gave the total number of opportunities for error (TOE), and this ensured that the error rate would not exceed $100 \%$. $^{6,10}$

All data collected were entered into and analyzed using the PASW Statistics for Windows version 18 (SPSS Inc., Chicago, IL, USA). Univariate analysis was performed on categorical variables, which could be associated with drug administration errors, using Pearson's chi-square tests. Further analysis to account for any compounding factors was performed using binary logistic regression. Any $P$-value $<0.05$ was considered as statistically significant.

All the drug administration errors were classified into four categories: Grade 1, probably clinically insignificant; Grade 2, minimal clinical significance; Grade 3, definitely clinically significant and could cause patient harm and Grade 4, potentially life-threatening. ${ }^{25}$ The classification was done independently by a pharmacist and a pediatrician and compared using kappa statistics $\kappa^{26}$ A consensus on the final classification was derived with the help of another researcher.

\section{Results \\ Characteristics of pediatric inpatients and drug administrations}

A total of 1,284 and 1,401 doses of drugs were administered in Phase 1 and Phase 2 of this study, respectively. 
Table I Characteristics of patients

\begin{tabular}{|c|c|c|c|c|}
\hline Characteristics & Phase I & Phase 2 & Combined & $\chi^{2}$ (P-value) \\
\hline No of patients (\%) & $217(5||)$. & $208(48.9)$ & $425(100.0)$ & $0.6174(0.535)$ \\
\hline \multicolumn{5}{|l|}{ Observer (Frequency [\%]) } \\
\hline I & 110 (50.7) & I I4 (54.8) & $224(52.7)$ & $0.722(0.396)$ \\
\hline 2 & 107 (49.3) & $94(45.2)$ & $201(47.3)$ & \\
\hline Median age in months ${ }^{c}$ (range) & $8.0(0.03-185.0)$ & $6.0(0.03-185.0)$ & $7.0(0.03-185.0)$ & $-0.870^{\mathrm{a}}(0.385)^{\mathrm{b}}$ \\
\hline \multicolumn{5}{|c|}{ Age group (Frequency [\% in each phase]) } \\
\hline Neonates: $0-27$ days & $39(18.8)$ & $55(28.5)$ & $94(23.5)$ & $8.060(0.045)^{*}$ \\
\hline Infants: 28 days-I year & $124(59.9)$ & $99(51.3)$ & $223(55.8)$ & \\
\hline Children: 2-II years & $35(16.9)$ & $36(18.7)$ & $7 \mid(\mid 7.7)$ & \\
\hline Adolescent: $12-16$ years & $9(4.3)$ & $3(1.6)$ & $12(3)$ & \\
\hline
\end{tabular}

Notes: ${ }^{a, b} Z$ and $P$-values obtained from the Mann-Whitney $U$ test. ${ }^{c}$ Assuming $I$ month is 30 days. $* P<0.05$.

The characteristics of patients whose drug administrations were observed are listed in Table 1. The patients were classified into four pediatric age groups, according to the International Conference on Harmonisation (ICH). ${ }^{27}$ Number of patients and doses observed in each ward and by the two different observers are presented in Tables 1 and 2. Doses administered by a nurse with and without wearing a medication apron (an apron with the wordings that the staff is serving medications so that other staff will not disturb him/her) as well as the three main routes of drug administration are listed in Table 2. The intravenous route included intravenous infusion and bolus injections. Other routes of drug administration included inhalation (using inhalers or nebulizers), ophthalmic, rectal and topical. For patients who were unable to take food and/or medications by mouth, medications were administered through an enteral feeding tube. All medications administered were classified into pharmacological groups based on the British National Formulary (BNF). ${ }^{28}$ The eight main groups of medications used in Phase 1 and Phase 2 are listed in Table 2.

Table 2 Characteristics of the drug administrations

\begin{tabular}{|c|c|c|c|c|}
\hline Characteristics & $\begin{array}{l}\text { Phase I, } \\
\text { frequency (\%) }\end{array}$ & $\begin{array}{l}\text { Phase 2, } \\
\text { frequency (\%) }\end{array}$ & $\begin{array}{l}\text { Combined, } \\
\text { frequency (\%) }\end{array}$ & $\chi^{2}$ (P-value) \\
\hline No of doses observed & $\mathrm{I}, 284(47.8)$ & $1,40 \mid(52.2)$ & $2,685(100)$ & $-3.1932(0.0014)^{* *}$ \\
\hline \multicolumn{5}{|l|}{ Ward } \\
\hline Ward A & $457(35.6)$ & $549(39.2)$ & $1,006(37.5)$ & \multirow[t]{2}{*}{$3.694(0.055)$} \\
\hline Ward B & $827(64.4)$ & $852(60.8)$ & $1,679(62.5)$ & \\
\hline \multicolumn{5}{|l|}{ Observer } \\
\hline I & $573(44.6)$ & $725(51.7)$ & $\mathrm{I}, 298(48.3)$ & \multirow[t]{2}{*}{$13.610(<0.001)^{* *}$} \\
\hline 2 & $711(55.4)$ & $676(48.3)$ & $\mathrm{I}, 387(5 \mathrm{I} .7)$ & \\
\hline \multicolumn{5}{|c|}{ Administration rounds (hours) } \\
\hline 08:00 & $605(47.1)$ & $596(42.7)$ & $\mathrm{I}, 20 \mathrm{I}(44.8)$ & \multirow[t]{4}{*}{$16.236(0.001)^{* *}$} \\
\hline $12: 00$ & $262(20.4)$ & $372(26.6)$ & $634(23.6)$ & \\
\hline $16: 00$ & $205(16.0)$ & $192(13.7)$ & $397(14.8)$ & \\
\hline $18: 00$ & $212(16.5)$ & $237(17.0)$ & $449(16.8)$ & \\
\hline \multicolumn{5}{|l|}{ Staff with medication apron } \\
\hline Yes & $561(46.2)$ & $608(45.2)$ & $\mathrm{I}, \mathrm{I} 69(45.7)$ & \multirow[t]{2}{*}{$0.24 I(0.623)$} \\
\hline No & $654(53.8)$ & $737(54.8)$ & I,39| (54.3) & \\
\hline \multicolumn{5}{|l|}{ Routes of administration ${ }^{\mathrm{a}}$} \\
\hline Oral & $402(3 I .1)$ & $427(30.5)$ & $829(30.9)$ & $0.216(0.642)$ \\
\hline Nasogastric & $393(30.6)$ & $382(27.3)$ & 775 (28.9) & $3.643(0.056)$ \\
\hline Intravenous & $302(23.5)$ & $403(28.8)$ & $705(26.3)$ & $9.519(0.002)^{* *}$ \\
\hline \multicolumn{5}{|c|}{ Groups of medication used ${ }^{a}$} \\
\hline Antibacterial drugs & $332(25.9)$ & 409 (29.2) & $74 \mid(27.6)$ & $3.733(0.053)$ \\
\hline Vitamins and minerals & $259(20.2)$ & $253(18.1)$ & $512(19.1)$ & $1.938(0.164)$ \\
\hline Bronchodilators & $132(10.3)$ & $100(7.1)$ & $232(8.6)$ & $8.382(0.004)^{* *}$ \\
\hline Diuretics & $80(6.2)$ & $64(4.6)$ & $144(5.4)$ & $3.648(0.056)$ \\
\hline Analgesics & $77(6.0)$ & $71(5.1)$ & $148(5.5)$ & I.I I0 (0.292) \\
\hline Antiemetics & $47(3.7)$ & $74(5.3)$ & $121(4.5)$ & $4.093(0.043)^{*}$ \\
\hline Corticosteroids & $39(3.0)$ & $51(3.6)$ & $90(3.4)$ & $0.752(0.386)$ \\
\hline Antisecretory drugs & $32(2.5)$ & $64(4.6)$ & $96(3.6)$ & $8.375(0.004)^{* *}$ \\
\hline
\end{tabular}

Notes: ${ }^{a}$ Only the main categories are shown in this table, and hence, the total does not add up to $100 \%$. $* P<0.05$. $* * P<0.0$ I. 


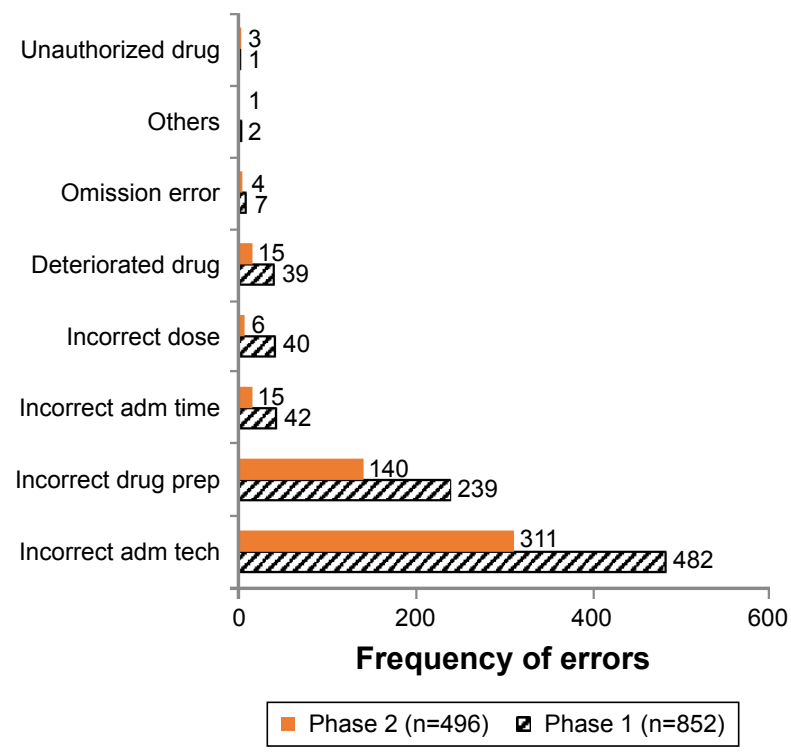

Figure I Types of drug administration errors in both Phase I and Phase 2. Abbreviations: adm, administration; prep, preparation; tech, technique.

\section{Drug administration error rate}

Of the 1,284 doses of drugs administered or opportunities for error in Phase 1, 569 doses had at least one error, giving an error rate of $44.3 \%$ (95\% confidence interval [CI]: 41.6, 47.0).
When incorrect administration time was excluded, the error rate reduced to $41.1 \%$. Whereas, when nasogastric and intravenous routes were excluded, the total number of doses observed became 589 and the number with errors was 119 , reducing the error rate to $20.2 \%$.

A total of 1,401 doses of drugs were administered in Phase 2 of this study, and 400 doses had at least one error. This gives an error rate of $28.6 \%$ (95\% CI: $26.1,30.9$ ). A significant association was found between the error rates and whether the drugs were administered in Phase 1 or Phase $2\left(\chi^{2}=72.19\right.$, $P<0.001$, odds ratio $[\mathrm{OR}]=1.99$ with $95 \% \mathrm{CI}=1.70,2.34)$.

\section{Types of drug administration errors}

Some doses of medications administered had more than one error. In Phase 1, a total of 852 errors were observed, whereas there were 496 errors in Phase 2. The different types of errors observed in both phases are shown in Figure 1, with examples given in Table 3.

\section{Factors associated with drug administration errors}

Several factors (phase of the study, ward under study, observer involved, use of medication apron, administration

Table 3 Examples of each type of drug administration errors in Phase I

\begin{tabular}{|c|c|}
\hline Type of error (frequency) & Examples of drug administration errors (frequency) \\
\hline \multirow[t]{6}{*}{ Incorrect administration technique (482) } & - Did not flush NG tube between NG drugs and before or after adm (233) \\
\hline & - No pre-flushing prior to/after IVB/IVI adm (49) \\
\hline & - Fast IVB - given in $10 \mathrm{~s}$ instead of a few minutes $(50)$ \\
\hline & - Did not swab injection port/site (II8) \\
\hline & - Incorrect MDI adm (8) \\
\hline & - Did not practices contact precaution/handwash (I0) \\
\hline \multirow[t]{6}{*}{ Incorrect preparation (239) } & - Leftover of drugs in mortar (II) \\
\hline & - Did not dilute drug prior to NG adm (24) \\
\hline & - Did not shake extemporaneous/ready-mixed suspension (6I) \\
\hline & - Did not observe aseptic procedure when preparing IV drug (3) \\
\hline & - Did not label the drug when more than one was prepared (16) \\
\hline & - Did not remove bubbles in IVI/IVB prep (45) \\
\hline \multirow[t]{4}{*}{ Incorrect administration time (42) } & - Fluticasone given $4 \mathrm{~h}$ late \\
\hline & - IVI ceftriaxone given $2.5 \mathrm{~h}$ late \\
\hline & - IVI benzylpenicillin given $3 \mathrm{~h}$ late \\
\hline & - Paracetamol given at 14:30 h, should be at 08:00 h \\
\hline \multirow[t]{6}{*}{ Incorrect dose (40) } & - Carbamazepine: given 180 mg instead of 150 mg \\
\hline & - Gentamicin: increased to $40 \mathrm{mg}$ but given $30 \mathrm{mg}$ \\
\hline & - Nystatin: given I mL instead of $0.5 \mathrm{~mL}$ \\
\hline & - Erythromycin: given 800 mg instead of 500 mg \\
\hline & - Benzylpenicillin: given I mL instead of $0.8 \mathrm{~mL}$ \\
\hline & - Ursodeoxycholic acid: given $30 \mathrm{mg}$ instead of $60 \mathrm{mg}$ \\
\hline \multirow[t]{2}{*}{ Deteriorated/expired drug (39) } & - Frusemide ( $24 \mathrm{~h}$ expiry) given after $>4$ days \\
\hline & - Captopril ( $24 \mathrm{~h}$ expiry) given 2 days later \\
\hline Omission error (7) & - Frusemide and spironolactone not given \\
\hline \multirow[t]{2}{*}{ Others (2) } & - Incorrect frequency \\
\hline & - IVI cloxacillin placed at inappropriate place \\
\hline Unauthorized drug (I) & - IVB Augmentin ${ }^{\circledR}$ (amoxicillin and clavulanate potassium) given to wrong patient \\
\hline
\end{tabular}

Abbreviations: NG, nasogastric; adm, administration; IVB, intravenous bolus; IVI, intravenous infusion; s, seconds; MDI, metered-dose inhaler; h, hours. 
Table 4 Factors that were associated with drug administration errors

\begin{tabular}{|c|c|c|c|c|}
\hline Step 9 analysis & Total no of doses ${ }^{a}$ & Frequency of errors (\%) & Wald ( $P$-value) & Adjusted OR $(95 \% \mathrm{Cl})$ \\
\hline \multicolumn{5}{|l|}{ Phase of the study } \\
\hline 1 & 1,215 & $5 I I(42.1)$ & II $4.954(<0.001)^{* *}$ & $2.98 I(2.44 I, 3.640)$ \\
\hline 2 & $|, 34|$ & $356(26.5)$ & & \\
\hline \multicolumn{5}{|l|}{ Ward } \\
\hline A & 953 & $342(35.9)$ & $19.989(<0.00 \mathrm{I})^{* *}$ & I.642 (I.32I, 2.04I) \\
\hline B & 1,603 & $525(32.8)$ & & \\
\hline \multicolumn{5}{|l|}{ Observer } \\
\hline I & 1,227 & $554(45.2)$ & $181.683(<0.00 \mid)^{* *}$ & $4.055(3.308,4.97 I)$ \\
\hline 2 & 1,329 & $313(23.6)$ & & \\
\hline \multicolumn{5}{|l|}{ Routes of $\mathrm{adm}^{\mathrm{b}}$} \\
\hline Nasogastric & 775 & $394(50.8)$ & $291.563(<0.00 \mathrm{I})^{* *}$ & $9.337(7.225,12.066)$ \\
\hline Other routes & $|, 78|$ & $473(26.6)$ & & \\
\hline Intravenous & 580 & $293(50.5)$ & $49.186(<0.001)^{* *}$ & $3.905(2.668,5.713)$ \\
\hline Other routes & 1,976 & $574(29.0)$ & & \\
\hline \multicolumn{5}{|l|}{ Medications used ${ }^{\mathrm{b}}$} \\
\hline Antibacterial drugs & 643 & $322(50.1)$ & $32.77 \mathrm{I}(<0.00 \mathrm{I})^{* * *}$ & $2.899(2.013,4.173)$ \\
\hline Other medications & 1,913 & $545(28.5)$ & & \\
\hline Corticosteroids & 84 & $26(31.0)$ & $6.825(0.009)^{* *}$ & $2.053(1.197,3.522)$ \\
\hline Other medications & 2,472 & $84 I(34.0)$ & & \\
\hline
\end{tabular}

Notes: ${ }^{a}$ The total number of doses in this table may be less than the original number due to missing data in some of the variables, and hence, 129 cases had to be excluded

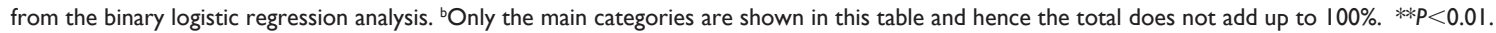

Abbreviations: $\mathrm{OR}$, odds ratio; $\mathrm{Cl}$, confidence interval; adm, administration.

time, route of administration and group of medication used) were included in the binary logistic regression analysis for any association with drug administration errors. The ninestep analysis showed that the study phase, the ward, the observer, use of antibacterials and corticosteroids, as well as nasogastric and intravenous routes were significantly related to drug administration errors (Table 4).

\section{Clinical significance of drug administration errors}

The drug administration errors were classified into four categories of clinical significance with examples (Table 5).
A kappa statistics $\kappa$ of $0.303(P<0.001)$ and $0.365(P<0.001)$ was obtained for Phase 1 and Phase 2 classification, respectively. These values indicate fair agreement between the two assessors for both phases of this study. ${ }^{26}$ The clinical significance of the errors was similar in both phases of the study $\left(\chi^{2}=6.477, P=0.091\right)$.

\section{Discussion}

The intervention of sharing information on drug administration errors with the ward staff was significantly associated with a reduction in such errors (from $44.3 \%$ to $28.6 \%$, $P<0.001)$. This was confirmed with the logistic regression

Table 5 Clinical significance of drug administration errors

\begin{tabular}{|c|c|c|c|c|}
\hline Clinical significance & Examples & $\begin{array}{l}\text { Phase I }(n=852) \text {, } \\
\text { frequency }(\%)\end{array}$ & $\begin{array}{l}\text { Phase } 2(n=496), \\
\text { frequency }(\%)\end{array}$ & $\begin{array}{l}\text { Total }(n=I, 348) \text {, } \\
\text { frequency }(\%)\end{array}$ \\
\hline Grade I & $\begin{array}{l}\text { Calciferol, captopril, ferrous sulfate, folic acid and } \\
\text { ibuprofen given }>\text { I h late }\end{array}$ & $56(6.6)$ & $18(3.6)$ & $74(5.5)$ \\
\hline Grade 2 & $\begin{array}{l}\text { No pre-/post-flushing of injections } \\
\text { Antibiotics given }>I \text { h late } \\
\text { Underdose of calciferol, promethazine and paracetamol } \\
\text { Did not shake antibiotic suspension } \\
\text { Medication left in the mortar }\end{array}$ & $448(52.6)$ & $256(51.6)$ & $704(52.2)$ \\
\hline Grade 3 & $\begin{array}{l}\text { Incorrect labeling } \\
\text { Fast IVB } \\
\text { Overdose of nystatin and paracetamol } \\
\text { Underdose of digoxin and gentamicin }\end{array}$ & $345(40.5)$ & $221(44.6)$ & $566(42.0)$ \\
\hline Grade 4 & $\begin{array}{l}\text { Overdose of carbamazepine } \\
\text { Overdose of domperidone } \\
\text { Fast IVB of vitamin K }\end{array}$ & $3(0.3)$ & $\mathrm{I}(0.2)$ & $4(0.3)$ \\
\hline
\end{tabular}

Notes: Grade I: probably clinically insignificant. Grade 2: minimally clinically significant. Grade 3: definitely clinically significant. Grade 4: life-threatening. Abbreviations: h, hour; IVB, intravenous bolus. 
analysis where the adjusted odds of drug administration errors in Phase 1 were almost three times than those in Phase 2 $(P<0.001)$. This indicates that if the ward staff is aware of the types of drug administration errors that occurred in the wards, the error rate can be reduced significantly. Therefore, the sharing of information on drug administration errors is an effective and simple strategy to reduce such errors.

The error rate of $44.3 \%$ in Phase 1 of this study is higher than other direct observational studies. ${ }^{4-11}$ This may be attributed to the inclusion of nasogastric tube-related and intravenous administration errors. If these two routes of administration were excluded, then the error rate for Phase 1 of this study decreased to $20.2 \%$, which is closer to most of the previous studies that excluded either or both routes of administration. A previous study in the same hospital reported a much lower drug administration error rate of $11.7 \% .^{6}$ This is probably due to the large number of nasogastric and intravenous administrations in this latter study, which contributed to a higher number of errors in drug preparation and drug administration technique. A study on drug administration errors by oral or nasogastric routes in pediatric inpatients also found a high error rate of $40.4 \%{ }^{5}$ In addition, the logistic regression analysis showed that the odds of drug administration errors were 9.3 and 3.9 times more with nasogastric and intravenous routes, respectively, compared to other routes of administration.

The most common types of drug administration errors found in this study were incorrect administration technique (mainly related to parenteral and nasogastric drug administrations), followed by incorrect drug preparation and incorrect administration time. Both phases had similar types of drug administration errors, but almost all the types reduced in frequency from Phase 1 to Phase 2 of this study (Figure 1). Similar types of drug administration errors had been reported by other studies. ${ }^{6,8,12}$

Incorrect administration technique involved not flushing the nasogastric tubes. This may result in tube occlusion, reduced drug bioavailability and efficacy, increased adverse effects, drug-drug interactions or drug-formula incompatibilities, as well as incurred costs related to increased morbidity. ${ }^{5,18,20,21,29}$ Hyperosmolar liquid formulations should be diluted to prevent delay in gastric emptying and risks of reflux as well as for the liquid preparations to flow more smoothly through the tubes. ${ }^{19,21}$ The hospital under study has standard operating procedures for nasogastric drug administration, but the flushing steps were often omitted in practice. Constant reminder and emphasis on the importance of following such procedures are essential to ensure that the quality and safety of medications administered are not compromised.

Wirtz et $\mathrm{al}^{30}$ considered doses administrated at a rate $15 \%$ faster than that recommended as an error. In Phase 1 of the present study, 50 out of 69 doses (72.5\%) given by intravenous bolus injections were given about 10-60 times faster than the rate recommended by the manufacturers or standard references. ${ }^{31}$ Rapid intravenous bolus injections may lead to speed shocks, resulting in headaches, flushed faces, syncopes or even cardiac arrests. ${ }^{32}$

Incorrect administration technique and incorrect preparation were mainly due to task-related conditions such as inadequate or not following standard administration protocols. Therefore, the development and implementation of hospital or national drug administration guidelines and protocol are essential. ${ }^{33}$ Individual-related causes such as lack of knowledge and awareness indicate the needs for continuing education and training for health care providers. .,6,33 $^{5,3}$

The difference between the carbamazepine dose prescribed and given may only be $30 \mathrm{mg}$, but this constituted $20 \%$ higher than the prescribed dose and may have significant effect on the pediatric patient. The use of an appropriate syringe with the smallest capacity possible to measure and administer the dose required is recommended to reduce the size of dose error.

The results of the binary logistic regression showed that the ward under observation and the observers could affect the rate of errors detected. This was probably due to the different types of medications administered or the different staff involved in each ward. The difference between the observers could be attributed to the natural differences between each individual, and this included the ability to observe activities around them. However, these factors would not affect the comparison of error rates between Phase 1 and Phase 2 as the same wards and observers were used in both phases of this study. The routes of drug administration, especially nasogastric and intravenous routes, increased the risk of errors, which may be due to more manipulation involved in these routes of administration. Antibacterial drugs were commonly used in the pediatric wards, but administration of such medications seemed to increase the risk of errors. Therefore, special precautions should be observed in the administration of these medications.

The clinical significance of the reported drug administration errors was similar in Phase 1 and Phase $2(P=0.091)$. More than half of the errors were considered as of minimal clinical significance $(52.6 \%$ and $51.6 \%$, respectively). This finding corresponds to that of other studies. $6,9,10$ 
Nevertheless, $>40 \%$ of the errors in both phases could result in definitely clinically significant harm to the patients and a few errors were potentially life-threatening. These errors included overdose of carbamazepine and domperidone and the fast intravenous bolus administration of vitamin $\mathrm{K}$, which carries a risk of anaphylaxis. ${ }^{31}$

One of the main limitations of this study was that it involved only two pediatric wards in an urban major tertiary hospital, and hence, the results may not be generalizable to other hospitals. The short duration of the post-intervention phase in this study could not account for the sustainability of the results obtained. Most of the observations were made during busy medication administration rounds, and this may have affected the error rate. In addition, if more than two ward staff were administering medications to patients concurrently, some doses may have escaped observation. This study did not consider the possibility of staff moving from the two wards under study, which could affect the occurrence of medication errors, although this was probably very minimum as this study was conducted in less than one year. One of the main concerns of direct observation was the Hawthorne effect as the ward staff could have behaved differently when under observation. However, this effect seemed to disappear after the staff had been observed for a period of time as they tended to forget about being observed and returned to their normal selves. ${ }^{34}$ Observer bias could not be ruled out as the major disadvantages of observational study are that it is time consuming and human resource intensive; hence, the study can be very exhausting on the observer. ${ }^{35}$

\section{Conclusion}

Phase 1 of this study showed that the incidence of drug administration errors was higher than many of the previous studies, probably attributed to the high proportion of medications being administered via nasogastric and intravenous routes. However, sharing of the types of errors that had occurred was significantly associated with a reduction in drug administration errors. This calls for all health care providers and institutions concerned to share any incidents where medication safety could be threatened so as to learn from each other and to prevent or minimize future medication errors.

\section{Acknowledgments}

We are grateful to Sister Peramaie d/o Alagappan and Sister Putri Zawiyah binti Megat Yaacob as well as all the staff of the two pediatric wards under study for their cooperation and assistance. We like to express our appreciation to the
Department of Paediatrics, University of Malaya, for organizing the presentation, which allowed us to share our findings. We wish to thank Ms Nor Aqilah binti Hassim for helping in the data collection and Ms Samihah Mat Junoh for helping to key in the data. We also acknowledge the University of Malaya for funding this study(RG123/09HTM; PG057/2015A).

\section{Disclosure}

The authors report no conflicts of interest in this work.

\section{References}

1. Committee on Identifying and Preventing Medication Errors. In: Aspden P, Wolcott J, Bootman JL, Cronenwett LR, editors. Preventing Medication Errors: Quality Chasm Series. Washington, DC: National Academies Press; 2007.

2. Samaranayake NR, Cheung STD, Chui WCM, Cheung BMY. The pattern of the discovery of medication errors in a tertiary hospital in Hong Kong. Int J Clin Pharm. 2013;35(3):432-438.

3. The Joint Commission. Preventing Pediatric Medication Errors. Sentinel Event Alert 39. 2008. Available from: https://www.jointcommission. org/assets/1/18/SEA_39.PDF. Accessed November 22, 2016.

4. Alsulami Z, Choonara I, Conroy S. Paediatric nurses' adherence to the double-checking process during medication administration in a children's hospital: an observational study. $J$ Adv Nurs. 2014;70(6): 1404-1413.

5. Bertsche T, Bertsche A, Krieg E-M, et al. Prospective pilot intervention study to prevent medication errors in drugs administered to children by mouth or gastric tube: a programme for nurses, physicians and parents. Qual Saf Health Care. 2010;19(5):e26.

6. Chua SS, Chua HM, Omar A. Drug administration errors in paediatric wards: a direct observation approach. Eur J Pediatr. 2010;169(5): 603-611.

7. Conroy S, Appleby K, Rostock D, Unsworth V, Cousins D. Medication errors in a children's hospital. Paediatr Perinat Drug Ther. 2007; $8(1): 18-25$.

8. Ghaleb MA, Barber N, Franklin BD, Wong ICK. The incidence and nature of prescribing and medication administration errors in paediatric inpatients. Arch Dis Child. 2010;95(2):113-118.

9. Otero P, Leyton A, Mariani G, Ceriani Cernadas JM, Paient Safety Committee. Medication errors in pediatric inpatients: prevalence and results of a prevention program. Pediatrics. 2008;122(3):e737-e743.

10. Prot S, Fontan JE, Alberti C, et al. Drug administration errors and their determinants in pediatric in-patients. Int J Qual Health Care. 2005;17(5):381-389.

11. Raja Lope RJ, Boo NY, Rohana J, Cheah FC. A quality assurance study on the administration of medication by nurses in a neonatal intensive care unit. Singapore Med J. 2009;50(1):68-72.

12. Feleke Y, Girma B. Medication administration errors involving paediatric in-patients in a hospital in Ethiopia. Trop J Pharm Res. 2010; 9(4):401-407.

13. Ghaleb MA, Barber N, Franklin BD, Yeung VW, Khaki ZF, Wong ICK. Systematic review of medication errors in pediatric patients. Ann Pharmacother. 2006;40(10):1766-1776.

14. Gonzales K. Medication administration errors and the pediatric population: a systematic search of the literature. J Pediatr Nurs. 2010; 25(6):555-565.

15. Chedoe I, Molendijk H, Hospes W, Van den Heuvel ER, Taxis K. The effect of a multifaceted educational intervention on medication preparation and administration errors in neonatal intensive care. Arch Dis Child Fetal Neonatal Ed. 2012;97(6):F449-F455.

16. Greengold NL, Shane R, Schneider P, et al. The impact of dedicated medication nurses on the medication administration error rate: a randomized controlled trial. Arch Intern Med. 2003;163(19):2359-2367. 
17. Barker KN, Flynn EA, Pepper GA, Bates DW, Mikeal RL. Medication errors observed in 36 health care facilities. Arch Intern Med. 2002; 162(16):1897-1903.

18. Idzinga JC, De Jong AL, Van Den Bemt PMLA. The effect of an intervention aimed at reducing errors when administering medication through enteral feeding tubes in an institution for individuals with intellectual disability. J Intellect Disabil Res. 2009;53(11):932-938.

19. Williams NT. Medication administration through enteral feeding tubes. Am J Health Syst Pharm. 2008;65(24):2347-2357.

20. Van Den Bemt PMLA, Cusell MBI, Overbeeke PW, et al. Quality improvement of oral medication administration in patients with enteral feeding tubes. Qual Saf Health Care. 2006;15(1):44-47.

21. Beckwith MC, Feddema SS, Barton RG, Graves C. A guide to drug therapy in patients with enteral feeding tubes: dosage form selection and administration methods. Hosp Pharm. 2004;39(3):225-237.

22. Bruce J, Wong I. Parenteral drug administration errors by nursing staff on an acute medical admissions ward during day duty. Drug Saf. 2001; 24(11):855-862

23. Dean B, Schachter M, Vincent C, Barber N. Causes of prescribing errors in hospital inpatients: a prospective study. Lancet. 2002; 359(9315):1373-1378.

24. Tissot E, Cornette C, Limat S, et al. Observational study of potential risk factors of medication administration errors. Pharm World Sci. 2003;25(6): 264-268.

25. Stubbs J, Haw C, Cahill C. Auditing prescribing errors in a psychiatric hospital. Are pharmacists' interventions effective? Hosp Pharm. 2004; 11:203-206.

26. Altman DG. Practical Statistics for Medical Research. London: Chapman \& Hall/CRC; 1999.
27. International Conference on Harmonisation (ICH). ICH Harmonised Tripartite Guideline: Clinical Investigation of Medicinal Products in the Pediatric Population E11. 2000. Available from: http://www.ich. org/fileadmin/Public_Web_Site/ICH_Products/Guidelines/Efficacy/ E11/Step4/E11_Guideline.pdf. Accessed September 10, 2014.

28. The Joint Formulary Committee. British National Formulary. 69th ed. London: BMJ Group and the Royal Pharmaceutical Society of Great Britain; 2015.

29. Boullata JI. Drug administration through an enteral feeding tube. Am J Nurs. 2009;109(10):34-42.

30. Wirtz V, Barber ND, Taxis K. An observational study of intravenous medication errors in the United Kingdom and in Germany. Pharm World Sci. 2003;25(3):104-111.

31. Plymouth Community Healthcare CIC. Procedures for Adminstering Injectable Drugs. Vol. V2. Plymouth Hospitals NHS Trust; 2013. Available from: https://www.scribd.com/document/292353090/InjectableDrugs-Monographs-v2. Accessed September 3, 2015.

32. Doyle GR, Mccutcheon JA. Complications related to parenteral medications and management of complications. Clinical Procedures for Safer Patient Care. (Chap. 7.7). Victoria, BC: BCcampus, B.C. Open Text Book Project; 2012.

33. Ozkan S, Kocaman G, Ozturk C, Seren S. Frequency of pediatric medication administration errors and contributing factors. J Nurs Care Qual. 2012;26(2):136-143.

34. Barker KN. Data collection techniques: observation. Am J Hosp Pharm. 1980;37(9):1235-1243.

35. Flynn EA, Barker KN. Medication error research. In: Cohen MR, editor. Medication Errors. Washington, DC: American Pharmaceutical Association; 1999:13-16.
Therapeutics and Clinical Risk Management

\section{Publish your work in this journal}

Therapeutics and Clinical Risk Management is an international, peerreviewed journal of clinical therapeutics and risk management, focusing on concise rapid reporting of clinical studies in all therapeutic areas, outcomes, safety, and programs for the effective, safe, and sustained use of medicines. This journal is indexed on PubMed Central, CAS,

\section{Dovepress}

EMBase, Scopus and the Elsevier Bibliographic databases. The manuscript management system is completely online and includes a very quick and fair peer-review system, which is all easy to use. Visit http://www.dovepress.com/testimonials.php to read real quotes from published authors. 